A peer reviewed open access journal indexed in NepJol; ISSN 2542-2596

Published by Molung Foundation, Kathmandu, Nepal

Article History: Received on 15 March 2021; Accepted on 26 May 2021

DOI: $\underline{\text { https://doi.org/10.3126/mef.v11i0.37836 }}$

\title{
Devaluation of Cultural Life: A Study of Reconstruction-Resilience Practices of an Earthquake Displaced Community
}

\author{
Madhu Giri \\ Tribhuvan University, Kirtipur, kathamndu Nepal
}

\begin{abstract}
Author Note
Dr. Madhu Giri is Assistant Professor of Anthropology in the Central Department of Anthropology at Tribhuvan University, Kathmandu, Nepal. He was awarded $\mathrm{PhD}$ in Anthropology from Tribhuvan University, in 2018. Besides teaching, he has carried out many research projects on the issues of caste/ethnic transformations, identity, Dalits, landlessness, public spheres, disaster resilience, religion, and social movements of different marginalized communities and written research articles published in different journals. Email: madu.giri@gmail.com
\end{abstract}




\begin{abstract}
This article investigates how earthquake reconstruction was practiced without considering socio-cultural values in the dislocated community after the 2015 earthquake. The process of disaster resilience tended to focus only on technical structures like the number of houses and school buildings as the main indicators of recovery from earthquake. The resilience programs conducted by the government and NGOs did not pay due attention to caste/ethnic tensions, religious division, political clash, and cultural loss among the villagers. In this study I thus wanted to know what were the meanings/ interpretations of reconstruction and community resilience; how reconstruction programs considered socio-cultural resilience; what socio-cultural aspects in practices of reconstruction were missing, and what were the challenges of cultural resilience among the displaced communities. The study was done at Kunchok-Nabalpur of Sidhupalchok. Local people's perspectives of reconstruction, values, cultural life (ethnographic study) and narratives were collected by using observation, interview, case study and field visit methods. The study found that caste/ethnic, religious and cultural cohesion had not been reinstalled. Socio-cultural diversity and diverse social needs of displaced people were ignored by the resilience programs of the government. This shows how technocratic reconstruction programs were not as effective as expected due to the devaluation of socio-cultural life of the disaster displaced people who otherwise could contribute to the policy and programs of sustainable and inclusive development of the society.
\end{abstract}

Keywords: disaster, displacement, reconstruction, devaluation, sociocultural life 


\section{Devaluation of Cultural Life: A Study of Reconstruction-Resilience Practices of an Earthquake Displaced Community}

There is a wealth of statistics of the huge damage caused by a devastating earthquake of M 7.9 Richter scale in April-May 2015 in Nepal. According to the Nepal Reconstruction Authority (NRA, 2018), 8,970 people died, 22,300 people were seriously injured and approximately 800,000 houses were destroyed. Based on the research of a village this article focuses on the damage in the village of Kunchok, in Sindhupalchok distrct under Bagmati Province killing over sixtythree people and destroying all (800) houses.

When I went to Kunchok Ward no 2 of Indrawati village municipality of Sindhupalchok in June 2018, people were unsettled. Most of them were living under temporary tin-roof huts. Balbhadra Bharati, a 65 years old man who lost his wife in earthquake, said that all of the villagers were displaced in different ways. He added that there were both temporarily and permanently displaced villagers at Kunchok. He said:

All houses and school buildings collapsed. Thirty-six people died, and about 100 were injured in the village. Survivors were engaged in either medication of the injured or management of dead bodies. The entire village was found unsafe because crack-lines on the earth's surface were visible everywhere. After a couple of days, survivors lived under the tent provided by the government and non-governmental agencies. After a couple of months government-supported a tin-roofed hut for the survivors. I am still living under the hut and waiting to return to new house. I am tired of making official papers and living in the temporary hut. Some survivors were compelled to leave the settlement area and trying to relocate to a new place. The Rural Municipality bought public land and relocated permanently displaced people of the village. 
Simple though it looks, this narrative indicates the uncertainty and frustration amidst the little hope of earthquake displaced people. A geological survey identified 136 settlements needing relocation. National Reconstruction Authority formulated and implemented different policies and guidelines for the consistency of reconstruction, community resilience, and equal distribution of resources. Processes of community resilience were technically measured in terms of the reconstruction of a number of houses and other physical structures. Media also described the earthquake resilience through technical science, geological location of safety, and danger zones.

The paper is divided into four sections. After the following introductory remark in this section, the second part sets theoretical approach and conceptual framework for the research. Then the third part of the article provides detailed ethnographic contexts of the field where reconstruction/resilience programs were continued in the aftermath of the earthquake. The last section synthesizes major findings of the research.

\section{Resilience and Reconstruction}

The term 'resilience' or 'recovery' is often confused with 'reconstruction.' The etymological meaning of reconstruction refers to construction of physical infrastructures like houses, schools, roads, and cultural sites. Resilience not only encompasses the reconstruction of physical structures but also reinstatement of livelihood activities and restoring community life (Central Department of Anthropology, 2020). While scientific explanations were dominant narratives in public space, another perspective, grounded in the social analysis of disasters, argued that disasters were not just natural; instead, they were tied to the development trajectory of a country and to the way development created multifaceted sources of vulnerability. In other words, a disaster was the consequence of poor or inadequate development. It captured the idea that disasters were historical products born out of the human agency and that they expressed the 
conditions of risk and vulnerability that the societies created and lived in. Many households were displaced, and they were planning to relocate new settings at Nawalpur with the help of the local government. Socio-cultural and political dimensions of resilience were overlooked in the narratives of both by government and media.

This study has been done through ethnography which provides a link to the past for the present diversity and contexts. Ethnography is current history that is not only informed by the past but something that will also indicate the outline of the emerging moments (Shah, 2004). The advent of ethnographic methods, including narrative, has greatly elucidated the articulations of disaster resilience and microcosmic social organizational shifts and adjustments that occur.

The primary purpose of this study is to identify the situation of the displaced people and to analyze the devaluation of the socio-cultural life of disaster displaced people and deficiencies of policies and practices in the multicultural communities. This study is based on both primary and secondary data. Local people's perspectives of reconstruction, values, cultural life (ethnographic study), and narratives were collected by using observation, interviews and case methods.

\section{Disaster and Social Vulnerability}

Vulnerability is political-economic phenomenon of the society. After natural or human induced disaster events, another disaster starts because of socioeconomic, political conditions of particular groups of people. A large number of people may be killed, displaced or affected by the socio-political causes at post disaster context (Gamburd, 2014). The deteriorating social context is regarded as disaster after disaster by many anthropologists (Gamburd, 2014; Oliver-Smith \& Hoffman, 2002). Displacement of large populations and their resettlement are embedded concerns of social vulnerability. The relationship between the physical and social aspects of vulnerability has been acknowledged by numerous scholars. 
Physical vulnerability results from location concerning to potential hazards, poor or inadequate construction of buildings, age of structures, and so forth. The social vulnerability involves the relative ability of an individual, household, or community capacity to respond appropriately to threatening conditions (Levine et al., 2007). Lack of income, lack of transport, age, gender, minority status, lack of information, and numerous other factors may cause to social vulnerability. Several authors (Bogard, 1989; Cutter, 1993; Cutter \& Emrich, 2006; Dow, 1992; Downing, 1991; Smith, 1992) have noted that vulnerability is a function not only of immediate physical conditions, but also of society's capacity to withstand disasters. Bohle et al. (1994) and Dow and Downing (1995) define vulnerability as a multi-dimensional construct captured in physical, and socioeconomic factors. Other research has integrated social response with physical risks in a wide array of spatial contexts (Degg, 1993; Lewis, 1987; Liverman, 1990; Longhurst, 1995; Mitchell et al., 1989; Palm \& Hodgson, 1992).

Ideally, post disaster vulnerability assessment should incorporate a wide range of factors: age, disability, family structure, and social networks, immobility, housing and the built environment, land ownership, population densities, income and material resources, the availability and affordability of property insurance, critical lifelines, occupation, and race and ethnicity (Burby et al., 2003; Chang, 2001; Clark et al., 1998; Cutter et al., 2003; Fothergill \& Peek, 2004; Kunreuther, 1998; Lewis, 1987). The NRA and non-governmental agencies developed indicators for the vulnerability assessment but they were practically not implemented in the field. They instead count family or household, injured population, dead number of people, and damaged number of houses. A similar approach has been used to claim recovery/reconstruction of the society. There was no assessment of social and cultural indicators of recovery.

Socio-cultural and political dimensions of resilience were overlooked in the narratives of both government and media. This paper concerns the tenacity of 
a binary way of framing post-disaster reconstruction between so-called "physicalist" and "social” approaches (Sliwinski, 2017, p. 263). In the case of Gujarat Earthquake reconstruction, social and cultural aspects of the community were not only ignored but also humiliated and hegemonized through political and economic symbols of modernity (Simpson, 2013). Similarly, Marchezini (2015) argued that disaster survivors had experienced various forms of social death caused by the policies and practices of some governmental agencies. All the analysis stressed that state organizations have biopolitical discourses and practices that consider local cultures irrelevant or irrational. This theoretical framework is applicable for analysis of the research.

\section{Initial Resilience Activities}

To get the most effective resilience, different approaches in different phases are required. The long-term resilience is connected with what happens at the beginning of the disaster. While assistance in the emergency is needed to save lives, uncoordinated, rushed and top-down approaches are employed at the village. Uma Giri, a 50 years old displaced woman, said that many strangers came with food and a tent after a couple of days of the earthquake disaster. They distributed things 'first come first receive' basis. They provided whatever they brought without making systematic rules. Roadside dwellers received five times more than off-road villagers. Narayan Bharati, 71-year-old man, said that they were discriminated against by the donor because their tents and huts were far away from the road side. Most of the relief distributors did not walk away from the road. He said that off-road villagers were compelled to live near their land because they had livestock and helpful neighbours. Sherpi Tamang, one of the remote dwellers, said that people did not allow others to make tent at their private land at the roadside. Most of the relief donors did not walk into the inner part of the village. He said that most of the vulnerable people were from remote parts and marginal locations where the road had not been constructed. Listening to their 
stories, I came to know that roads proximity was an indicator of socio-economic resources. In remote village there was very good socio-cultural harmony. Kishor Ranamagar, a roadside dweller, said that people understood the values of road in the aftermath of the earthquake. The road is a boon for the roadside people because they received more relief material and built network with different newcomers. Roadside people knew much information because of the flow of people and the gathering of people around tea-shop around the road. Similarly, the road was profitable for the proximate dweller in terms of the labour fee of house construction materials.

Sliwinski (2017) referred to a materialistic perspective privileging a hazard approach to disasters (i.e., the disaster is equated to an exogenous event caused by a hazard) and technological procedures to fix damaged infrastructure such as houses, roads, schools and the like. Government through NRA allocated the same amount and material for roadside dwellers and remote dwellers, middle class, and lower class, all castes and differently-abled people. Socio-economic, gender, caste/ethnic and lifeline assessments have not been done before launching recovery and reconstruction programs. In this context, the Government of Nepal formulated and employed monolithic and physicalist policies for the reconstruction of the earthquake disaster. Uma Giri again said that the early free handouts heightened expectations on what comes next, subsequently, negatively influenced people's self-reliance and creates dependency. Everyone talked about mechanism of receiving instalments, construction expenditure, number of labour and amount they received from government. Villagers tried to meet criteria set by the government and local technicians. They visited at ward office and filled form for the next phase.

Both government and technicians oriented physicalist model (Sliwinski, 2017) of resilience to the displaced people. Uma added that system of Parma (labour sharing), food sharing at neighbours, oxen sharing systems completely 
disappeared in the aftermath of the earthquake. These systems strengthened social and cultural harmony among the villagers. A number of dead persons, beneficiaries, completed houses, school rooms, and roads were counted by the technicians and political leaders. Politically active and powerful villagers received and stored unnecessary materials. They did not talk about the restoration of Tamang's worshiping place at new settlement. Before distribution of relief materials, none of the recovery teams was concerned about caste/ethnicity, gender, disability, poverty and occupational status of the villagers. The support materials also distributed uniformity without considering their number of family members and economic status of the family. Therefore, it can be argued that the resilience program is techno-centric.

\section{Permanent Displacement}

Two settlements were severely cracked and blocked on both sides by dry landslides. Four people died in the earthquake landslide. The geological study team suggested not making the house in a cracked location. There were eight families at a settlement. Most of the survivors ( 6 households) of the settlement had their own land at another site. They were relocated to their land. Their land was not close to the road. Because of distance from road and systems of drinking water, electricity, the location was not preferred for the settlement. Now, the earthquake compelled them to relocate the marginal location. The relocated survivors also relatively excluded from road access benefits. An old woman said that her family received the remaining relief materials. The relocated people did not get information and connection from the donors. After the Rural Municipality election, the displaced households received more material. The ward chairperson formed a committee for the inclusive distribution of relief and recovery support. Those ( 2 households) who had no land in another location were permanently displaced to public land. The permanently displaced were the highly marginalized households of the Tamang. Compared to the permanently displaced, temporarily 
replaced and relocated people at their own land were the survivors who found themselves culturally strong and socially united.

There were two categories of permanent displacement in the village. The first category of them was the group of people relocated in their land. The second category of displaced people has not their own land at other location. Compared to the second category, the first category received relatively more support from non-government agencies and local community. They continued previous livelihood occupation and strategies. They were connected to own ethnic group in terms of territory and cultural stuff. They lost materials and family members, but their stories sound optimistic. Biru Lama, 56 years old among the replaced persons, said that there was a satisfactory level of social security in the community. He shared that his neighbours cooperated for extension of the road, drinking water pipe and electricity at a new settlement without local government decisions. Some of them gave land and wood free of cost for road and temporary house construction.

Another permanently displaced settlement was alarmingly picaresque. Displaced persons were relocated at the community forestry land. There were no facilities of electricity, drinking water, and land for vegetable cultivation. When the policy of land acquisition was formed, the Rural Municipality designed a resettlement project for the permanently displaced villagers. At first, the survivor was reluctant to accept the resettlement project because they were not included in the process of decision making. The problem was top-down and non-participatory approaches were employed for the resettlement program. Ratna Tamang, a displaced old man shared that his family was about to resettle in the Tamang settlement, but the Rural Municipality decided to make a house in the new settlement. Displaced people were not given any option for the selection of settlement. Uttam BK, a permanently displaced man, expressed a similar tone in living near his kin people. 


\section{UNDP Program and Wage Increment}

After a couple of weeks, United Nations Development Program [UNDP] selected Kunchok for completely safe demolition/debris managed - both public and private buildings - in 3 VDCs (Kunchok, Irkhu, and Karthali) of Sindhupalchok. The concept of this Emergency Employment (Cash for Work) in the Early Recovery phase was to involve local communities to remove debris and safely demolish the houses, which was the immediate need of aftermath of such a great magnitude of earthquake for safety and pave the way for reconstructing both public and private buildings. They named it as UNDP's emergency employment. This program created 'hope' and recreated 'society' among most of the temporarily displaced survivors.

The concept of the program was derived from the physicalist model of resilience. The program did not support unity of community and inclusive participation of the survivors. Permanently displaced households and survivors who left the village for the medication of family members and took shelter at relatives in a different village and Kathmandu valley were excluded from the program. The inclusive development rhetoric of such a reputed international development agency overlooked issues of displacement and gender discrimination.

It was no free offering, however. 'Cash for Work' was regarded as 'dignity,' the community received the cash in exchange for their valuable contribution to community/own (private) house demolition/debris management at a crisis. If social workers were mobilized in the program, this could be an opportunity for the social and community recovery initiative. Engineers and technical experts were mobilized to mark and study the physical status of the location and houses.

The debris management and cleaning programs started from Shree Mahendra Higher Secondary School. This program was not limited to public 
structures, but also covered demolition and debris management of private homes. Dal Bahadur Bharati said that this type of program was experienced for the first time in his life. All working-age family members and some UNDP officials worked for debris management and cleaning up the damaged homes; all workingage family members were paid cash by UNDP officials. Villagers were surprised because they earned money/wage for cleaning of own broken homes. Many of them expressed that this was new phenomenon in the village. In comparison to pre-earthquake daily wage, the workers were paid two times more the wage. Before earthquake, the wage rates of the villagers were Rs. 350/400 for males and 300/350 for females. Uma Giri said that the UNDP paid Rs. 1000 for males and Rs. 800 for females.

This program was primarily dominated by a physicalist approach as Sliwinski (2017) claimed. Gender-based difference was noted because UN agencies advocated equal wages for equal work but did not practice it. The program was neither sustainable nor inclusive in terms of displacement, caste/ethnicity, and gender. Permanently displaced survivors did not need to demolish/debris management of their houses, therefore, they were excluded. Unruled and unhealthy competition of cash earning among the survivors raised tension among themselves. Working at own home and getting cash wage was an alien practice; therefore, everybody was interested to stand at working site. Bal Bahadur Bharati joked that both worker and disaster site viewer received the same wage. Long term consequence of the program was an increment in the wage rate in the village. The wage rate of the UNDP program became a common wage rate for males and females in the village. When the rate was established as standard wage rate, the expensive wage ratio was a headache for the middle-class farmer in the village. After this project, nobody was ready to work on low wage. Man Bahadur Giri had relatively more land. He needed farm labour occasionally. The agro-wage rate was expensive. He shared that he thought he had better leave 
agricultural land barren. In the beginning people were happy to receive a high wage rate. When they started to pay everyday wage for their farm work, they were not satisfied with the dramatic increase in the wage rate. As a consequence, there was a dearth of labour in the village right after the earthquake. Everybody was engaged in reconstructing their own home and agricultural activities. Those families who had not working-age members suffered a lot, and they were compelled to pay expensive wage rate.

Another consequence of high wage practice was the penetration of house construction contractors. Many of them were from outsiders. They brought large number of construction labours. Many labours were from Kalikot and Jajarkot districts. In the course of reconstruction, the local elite also started as contractors. Ram Bahadur Thapa, the headmaster of Mahendra Higher Secondary school, for example, became a contractor for house construction. He bought a tripper to carry hardware materials and contracted more than ten houses of the villagers. Mohan Bahadur Giri, the chairperson of the school management committee, said that $\mathrm{Mr}$. Giri was more businessman than teacher after the earthquake. Because of his engagement in the construction business, education quality and school system were ruined. When I was at the school office of Mr. Giri, he was busy on phone calls with his tripper driver. I also agreed that he and many teachers were completely turned entirely from teacher to businessman and contractor. The students also complained that he rarely presented in the class.

Many people started a new profession besides earlier professions and village politics. Their engagement in business created social and educational problems in the village. Teachers who were expected as role models of the village were involved in profit making business. Socio-cultural behaviours of the students were also found problematic. This economic and physical/material orientation of recovery hampered the social and educational resilience of the village. School buildings were reconstructed, but the quality of education was declined. Most of 
the villagers transferred their children to either Kathmandu or Chautara for better education including those of headmaster who now could afford to pay in expensive private schools in the cities.

\section{Reconstruction: Monolithic Model}

Reconstruction brought two important changes to the village. They are roadside houses and monolithic structures of the house. Most of the houses under construction made either one or two-rooms with similar structure and design. Though NRA authorized eight different models of house construction, local technicians promoted a single model. Their indirect promotion was single room cemented house. The smaller and one-room house was easily and quickly passed without an observational check of technicians, who behaved like the authoritative and highly welcomed persons in the village. One of the villagers said that there were varieties of arts, architecture, and structures of houses before the earthquake. They were made by older people most of whom already passed away and the rest could not work. He argued that those arts and architectures were lost forever. Their newborn children would observe only new style house in the village.

According to Man Bahadur Bharati (96 years old), new members of his family did not get an opportunity to observe the art and architecture of his old house, which was full of wooden art and structure like outer balconies. He stressed that stone roofed house would be a big surprise and strange for the coming generation. He added that stone slate-roofed houses were symbolic markers of prosperity, caste, and social status in the village. He remembered his heydays when lower caste people were not allowed to make slate-roofed houses. He further explained:

Bhotes (Tamangs) were poor and many of the Sanyasis had not stone roofed houses in the village. Recently (before 10 to 20 years) stone roofed house became a fashion among all caste ethnic peoples. Bhotes, Sanyasi, Magars and Dalits constructed stone roofed houses in the village. Then the 
earthquake destroyed the fashion, competition and differentiation. Now all of villagers were building uniform house. There was no caste ethnic, class and status differences. All are equal.

I observed slight differences. Economically well up households made big concrete house including own investment. The second layered people also made relatively different houses by borrowing money from their relatives and commercial institutions. Marginalized peoples made whatever government package covered. Highly marginalized were either excluded from the list of relief or processed for second instalment.

I also observed cases of corruption by the technicians who made commitments to the people after the arrival of instalments without meeting basic requirements for the next installment. One morning, Man Bahadur Giri, one of the local politicians, called me to observe the Dasnamai settlement at Puware. I met Sherpi Giri, the elected ward member from the previous Maoist party. Other people also gathered around when we were talking about resilience and the reconstruction process of the village. I was unfamiliar to many villagers. One of the villagers, who was drunk, was confused with my appearance. He thought that I was a technician. He proposed to pay Rs. 10000 to forward his file for the second instalment as bribe. When I did not pay attention, he again said, "I paid you whenever I got first Kista, believe me I will pay you again. Please, forward my file for the process of the second Kista". Then I realized that there were cases of corruption from technicians.

At the local level, technicians were the supreme authority of reconstruction so they governed the ecology of construction. Some of them made alliances with local elites who were social workers of NGOs and treated locally like NGO personnel. Khem Bahadur Nepali said that his name was excluded from the list of Rahat. He added that his family had been temporarily living out of the district. His land and other property were in the village. The coordinator and 
villagers did not list his name as the earthquake victim. After a couple of weeks, he came to check his name in the list of Rahat. The villagers and technicians denied his name because he was not in the village, and his family would not live in the village. Later, he filled complaint (Gunaso) form, but his complaint was not heard. He, as a member of Biswasi Mandali (a local Christian, member of a Church that was constructed at his uncle's land), went to the Chuch to get the support of the community. Lastly, his name was included in the list of Rahat.

First, the reconstruction project of government instalments supported and brought new settlement. Because of limited resources, people tried to manage within a given amount. If they used human labour to carry construction material from the road to the inner settlement, there would be more labour expenditure. I observed that there was road access at each newly made and under-construction house. The Ward chairperson also agreed that the primary source of budget distribution was the expansion of road access for all households. Newly-made roads changed the land and settlement pattern of the rural village. If the house was made off-road, it would cost high because of extra labour to carry construction material. Those people who had land close to the road transformed their previous house location. They left the old house and made a new home close to the road. Chairperson said that every household demanded road on his/her yard. The road at the yard was one of the markers of power and socio-economic status of the household. The landowners of roadsides turned economically powerful because they put many conditions and bargaining to the landlocked households. One Dasnami owner denied access to the road by cutting his land to the Dalit community. There were five Dalit households in the village. The Dalits filed the case. The case was not decided yet. The landowner said to me that if Dalits would buy his land, he was ready to sell. Bir Bahadur Tamang, the chairperson of the ward, said that there were various structures, wood art, and architecture house before the earthquake. Tamang's house and Sanyasi's house were different in 
structure, art, and architecture. These diversities of architecture disappeared after the earthquake. There is no difference between Tamang's Sanyasi' and Magar's newly made the house. Man Bahadur Bharati (90 years old man) said that house is not store made of soil, stone or cement-sand and iron. There must be an agreement of gods, local spirits, and human beings. Before making a house, a human must get consent from nature and god. He said that there was no consent of gods and spirits to make new house wherever people are making. He claimed that these newly made houses would be ghost houses after a few years. He added that there was a tradition of observation and study of the proposed house making place both physically and spiritually. Tin roof hut, warm clothes support, and land relocation policy were the second phase of recovery. This phase was a much more systematic distribution of materials.

\section{Reconstruction: Rhetoric and Reality}

Narayan Bharati showed me the village where massive houses were constructed. He told me that if I visited them before the earthquake, the picture of the village would be completely different. Traditional settlements and caste ethnic clusters were different. He again added that if I was in the village after six months of earthquake, the village would be set up as homogeneous tin-roofed huts. There was no caste, ethnic, and class differences. After two years of the earthquake, there was a dramatic reconstruction of houses and roads of different type. When the road and house were constructed, the household was listed as resilient. Road and house were the only indicators of reconstruction/recovery in the village. NRA's reports also stressed a number of houses and schools as main indicators of the recovery from the earthquake.

Man Bahadur Bharati said that villagers tried to receive government funds without any cost. They knew that the allocated budget was insufficient to reconstruct the house and other assets of the family. Some of them made houses and converted to shade/ goats' houses by the budget. An interesting aspect was 
that they named the new house as 'Government house'. It was exciting process of 'Othering' the construction. Many of them showed newly constructed and government-funded house because they thought that these visitors came to observe 'government houses'. When I started about the earthquake and reconstruction, they requested me to observe government houses made out of government funds.

Sanu Nepali said that he made a house, but his family members did not like to live in the narrow room. There was no space for the relatives who came home during the festivals. There was no space for the god and goddess. Ram Bahadur said that their culture was 'god first'. Many of the newly made houses were started without observing the fortune of god and evil spirits. The traditional culture of house construction was the astrological observation of the site for the good fortune of the family members. At the beginning of the foundation, a priest should worship and offer good and evil spirits. But this time, technicians and engineers identified the house construction site. They replaced astrologers, priests, and gods. Therefore, most of the villagers thought that government-made houses were not lucky for the family. Then, they started to keep goats and cows. The technical model of resilience thus created problems with the governmentsupported houses. The negligence of the local culture turned the human houses into a cow shed.

House construction was the only subject of observation on the project of reconstruction. Nobody paid attention to social and cultural reconstruction. Their public spaces were more commercial and profit-oriented. The social and cultural aspects of food and labor sharing were collapsed with the earthquake. Traditional norms and values of respect were lost. None of the authorities talked about the reconstruction of the old architectural aspect of the house, old social ties and cultural functions. 
Narayan Bharati said that this model of reconstruction was gender and kinship unfriendly. He added that there was no space for night stay for the guests and other family members who visited on festivals. He shared that his daughters and sisters complained that there was no space for an overnight stay for them. Two daughters and their four children visited on the occasion of Teej. He said, "In traditional house, there was sufficient space for guests and family members. Because of lack of sleeping space, daughters shortened their living with parents. Similar situations occurred in Dashain and Tihar. In Dashain, many relatives visited but they returned quickly for the same reason. If they stayed overnight, it would be uneasy to the host. There were only two small rooms. Women and girls felt uneasy to adjust with male members". He explained that preveiously there were extensive kinship relations in the village. Relatives were interested in staying with old peoples. Most single elderly people made one-room house. He questioned, "How close relatives like in-laws and could live overnight within a room?" Similarly, women and girls were mostly engaged in cooking in the kitchen and cleaning pots and clothes. There was no space for the kitchen and water management.

Therefore, the reconstruction project neglected villagers' kinship networks as well as gender relations in local contexts. Many villagers complained that this reconstruction planning devalued the social and cultural life of the community people. It was merely planned by technicians who counted only the number of humans in a household. But in the village, babies, dogs, goats, calves, and chicken have also to be adjusted within the same space allocated for humans. Dal Bahadur Bharati said that it was their great mistake to count human family members exclusively in the village resilience project. His argument was that village life was intricate with kinship relations and agrarian livelihood. Without understanding the complexity of village life, the project of resilience/ reconstruction would be unfinished or even if finished it would not as effective as it ought to be. 


\section{Conclusion}

The main conceptual framework of the NRA was that all people affected by earthquake, irrespective of their caste, ethnicity, gender, class, ability, religion, and region, were equal. The villages were heterogeneous, whereas formed policies treated them as having no caste, ethnic, power, and class differentiation. The major flaw of most of the policies was that they ignored inclusive clauses of fundamental rights section of the constitution, 2015 as well as inclusive provision of development guideline.

NRA of Government of Nepal, local authority, and most NGOs also considered resilience as construction of houses, roads, drinking water supply, electricity, and another technical requirement. But the displaced people have not only lost their place but also been shocked by the social networks and cultural practices of the new place. There was economical and technological domination of resilience programs. The resilience projects were heavily influenced by a certain type of value and the market-based development. Reconstruction programs weakened local diversity of knowledge and practices and strengthened market economy. None of the resilience programs were implemented to reconstruct the culture, knowledge, and social capitals of the displaced community. Reconstruction of cultural capitals, learning, social networks was ignored in the programs of community resilience among the displaced people.

Similarly, reconstruction regulation stated that technical engineers should pass the structure of the house before application for the next instalment. I have not seen any engineers in both the ward and village municipality offices during my fieldwork. Villagers and CTEVT technical students said that engineers did not visit wards and village municipality office. In ward, CTEVT students were authoritative personal to accept and reject proposal of the next instalment. They rarely visited villages and settlements to observe reconstruction processes and technical aspects. They mostly stayed at the ward office. When applicants came 
for the request of the next instalment, technicians demanded photos of the present status of the house. If some of the applicant did not meet the requirement of the NRA, technicians suggested going photoshop and asked to print two photos of the technically accepted structure. This is possible because the architectural and structural models of all houses are the same.

Moreover, the provisions of the next instalment application were also identical. Then, technicians passed the previous structure and proceeded the instalment. There is space for the signature of the engineer in the form. When I asked the technicians, they said that all forms were collected in the different villages and collected at the district headquarter. There is a coordination office where one or two engineers sign in all dead and application forms sent by the technicians. Without observation and visit of reconstruction field, they passed and proved that newly constructed house under Rahat package was safe and technically earthquake resilient. Displaced people are hierarchical in terms of power, prestige, and property whereas policies treated them equally. Therefore, most of the reconstruction and resilience programs perpetuated social hierarchy, domination of one group over the other, and inequality. Most of the reconstruction programs thus devalued the socio-cultural life of the displaced households and surrounding communities whereby causing failure to attain resilience.

\section{Acknowledgments}

This paper is developed from the findings of a research in which I was engaged as a researcher under the Small Research Development and Innovation Grant (SRDIG-75/76-H\&S-8) of UGC and 'State of Social Inclusion in Nepal' Grant of Central Department of Anthropology, TU. With the insights of that research I have critically discussed my observations in this paper linking my ideas with the available socio-cultural theories. I am thankful to these institutions for offering me this opportunity. 


\section{References}

Adams, V., Taslim V. H. \& Diana, E. (2009). Chronic disaster syndrome:

Displacement, disaster capitalism, and the eviction of the poor from New Orleans. American Ethnologist, 36(4), 615-636.

Bogard, W. C. (1989). Bringing social theory to hazards research: Conditions and consequences of the mitigation of environmental hazards. Sociological Perspectives, 31, 147-168.

Bohle, H. G., Downing, T. E. \& Watts, M. J. (1994). Climate change and social vulnerability: The sociology and geography of food insecurity. Global Environmental Change, 4, 37-48.

Burby, R. J., Steinberg, L. J. \& Basolo, V. (2003). The tenure trap: The vulnerability of renters to joint natural and technological hazards. Urban Affairs Review, 39 (1), 32-58.

Central Department of Anthropology. (2020). Community resilience capacity: A study on Nepal's 2015 earthquakes and aftermath. CDA.

Chang, H. (2001). Development of a comprehensive vulnerability assessment model using GIS [Doctoral dissertation]. Cornell University.

Cutter, S. L. (1993). Living with risk. Edward Arnold.

Cutter, S. L. and C. T. Emrich. (2006). Moral hazard, social catastrophe: The changing face of vulnerability along the hurricane coasts. Annals of the American Academy of Political and Social Science, 604, 102-112.

Cutter, S. L., B. J. Boruff, and W. L. Shirley. (2003). Social vulnerability to environmental hazards. Social Science Quarterly, 84(2), 242-261.

Degg, M. (1993). Earthquake hazard, vulnerability and response. Geography, 78, 165-170.

Dow, K. (1992). Exploring differences in our common future(s): The meaning of vulnerability to global environmental change. Geoforum, 23, 417-436. 
Dow, K. \& T. E. Downing, T.E. (1995). Vulnerability research: Where things stand. Human Dimensions Quarterly, 1, 3-5.

Gamburd, M. R. (2014). The golden wave: Culture and politics after Sri-Lanka's tsunami disaster. Indiana University Press.

Government of Nepal. (2014). Local disaster risk management planning.

Government of Nepal, United Nations Development Program \& European Commission. (2008). National strategy for disaster risk management in Nepal.

Lewis, J. (1987). Risk, vulnerability, and survival: Some post-Chernobyl implications of people, planning, and civil defence. Local Government Studies, July/August, 75-93.

Marchezini, V. (2015). The biopolitics of disaster: Power, discourses, and practices. Human Organization, 74 (4), 362-371.

Mitchell, J. K., Devine, N. \& Jagger, K. (1989). A contextual model of natural hazard. Geographical Review, 79, 391-409.

Ministry of Home. (2073 BS). Earthquake Report. Ministry of Home.

Oliver-Smith, A. \& Hoffman, S.M. (2002). Introduction: Why anthropologists should study disasters. In Anthony Oliver-Smith \& Susanna M. Hoffman (Eds.), Catastrophe and culture: The anthropology of disaster (pp. 3-24). School of American Research Press.

Palm, R. I. \& Hodgson, M. E. (1992). Earthquake insurance: Mandated disclosure and homeowner response in California. Annals of the Association of American Geographers, 82, 207-222.

Shah, S. (2004). A project of memoreality: Transnational development and local activism among rural women in Nepal [Doctoral dissertation]. Harvard University.

Simpson, E. (2013). The political biography of an earthquake: Aftermath and amnesia in Gujarat, India. Oxford University Press. 
Sliwinski, A. (2017). The resilience of physicalist paradigms: Revisiting post disaster reconstruction in El Salvador. Urban Anthropology, 46 (3), 261296.

Smith, K. (1992). Environmental hazards: Assessing risk and reducing disaster. Routledge. 